\title{
People, Places, and Health Variations: A Case of Malaria Incidence in Ibadan, Nigeria
}

\author{
'Yemi Adewoyin' and Aina Thompson Adeboyejo'
}

\author{
Department of Urban and Regional Planning, \\ Ladoke Akintola University of Technology, Ogbomoso, Nigeria \\ yemiadewoyin@yahoo.com
}

\begin{abstract}
This paper investigates the relationships between the population's levels of social well-being and places of residence, and how these underlie the incidence of malaria in a traditional African city. Using a stratified sampling technique with population density as the parameter, a total of 15 localities from the 5 metropolitan LGAs in lbadan typifying the low, medium and high density residential areas were selected for the study. Questionnaires were administered on I,084 randomly selected household heads. The data were analyzed using the Chi Square and One-Way Analysis of Variance (ANOVA) statistics, while the aggregated scores representing respondents' level of social well-being were correlated with the individual's household frequency of treating malaria using the Pearson Product Moment Correlation technique. The results indicate that residents of low density residential areas ranked highest in social well-being and had the best health outcomes evidenced by the lowest incidence of malaria among the three residential classes.
\end{abstract}

Keywords: Social Wellbeing, Socioeconomic Status, Malaria, Residential Density, Health Variations

\section{Introduction}

Against the background that social inequalities have a spatial variation, with many people who are on the lower pedestal of the socio-economic ladder living in not-so-good residential environments, having poor feeding habits made up of meals that are low in calories, and having constrained access to social infrastructure, and public goods and services, this paper investigates the relationships between the population's levels of social well-being and places of residence, and how these underlie the incidence and pattern of environmentally-induced diseases in a traditional African city. Specifically, the study seeks to explain the varying incidence and pattern of malaria along residential density lines in Ibadan, Nigeria as consequent on the population's social well-being.

Malaria is a public health problem today in more than 100 countries of the world inhabited by over 2.4 billion people (WHO, 2006; MFI, 2013; Nigeria, 20I3). According to the 2005 world malaria report, the number of deaths resulting from malaria is I million per annum. Malaria sickens between 350 and 500 million more people yearly and kills an African child every 30 seconds (WHO, 2005). In Nigeria, there are an estimated 100 million malaria cases annually with a resultant death of between 225,000 (Nigeria, 2013) and 300,000 people (WHO, 2006). Malaria accounts for $11 \%$ of maternal mortality in
Nigeria, $60 \%$ out-patients hospital visits, and $30 \%$ hospitalization among children under the age of 5 (Nigeria, 20I3, NMEP, 20I4). Its prevalence rate in Nigeria ranges from less than $1 \%$ among the dwellers around the mountains of Southern Jos, Plateau State, to as high as $90 \%$ among inhabitants around the rivers Niger and Benue (NMCP, 2009). In Oyo State, South-West Nigeria, where the study area is located, the prevalence rate is between $40 \%$ and $70 \%$ (NMCP, 2009).

Malaria abounds mainly in the tropics largely because of rainfall and high temperature. While the hot temperature of the tropics shortens the malaria vector (mosquito)'s breeding cycle thereby speeding its reproduction rate and lengthening the season during which mosquito abounds, rainfall on the other hand creates puddles of still water, a breeding ground for mosquitoes. These breeding grounds are mostly found in areas of poor drainage network, places of inadequate waste disposal systems, and neighbourhoods with poor living conditions which typify the high density residential areas in the urban centers. The high density residential areas are most often populated by people with lower socioeconomic status relative to their counterparts in the low density areas of the urban centers. 
Studies have shown however, that habitat conditions in residential areas have implications for exposure to or protection from diseases, and equally affect susceptibility or resistance to diseases (lyun, 1987; Meade et al, 1988; Egunjobi, 1995). Further, residential agglomeration has been attributed to income inequality and found to also have implications for health (Kawachi and Kennedy, 1997). Studies by Barker and Osmond (1991), Wilkinson (1992; 1996), Anderson and Armstead (1995), Kennedy et al (1996), Kaplan et al (1996), Kaplan (1996), BenShlomo et al (1996), and Macintyre et al (2002) also show that income inequality results in social segregation with negative implications for the population's health. Kennedy et al (1996), Kaplan et al (1996) and Shomo et al (1996) specifically relate the outcomes to increased mortality among the population. These studies focus on the people (composition) or the places (contexts) in providing explanations for the geographical variations in health. A third line of explanation which provides the linkages between the socio-economic status of the people and the ecological characteristics of where they live, and how these impact on the population's health is attempted in this work.

In providing this explanation, four interrelated research questions are addressed in this paper. These are; what is the spatial pattern of social wellbeing in the study area, is there a significant variation in levels of social wellbeing in the residential density categories, what is the pattern of household malaria incidence in the residential categories, and is there a significant correlation between levels of social wellbeing and the incidence of malaria in the study area. It is expected that the research findings will contribute to knowledge in diseases prevention and eradication, particularly as it relates to the Post-20I5 United Nations Development Agenda on health. One major approach, hitherto unrecognized in the actualization of the health MDGs is the need to address the social, economic and environmental determinants of health and their interrelationships and not just the proximal causes of illness and diseases (UN Task Team on the Post-20I5 UN Development Agenda, 2012).

Ibadan, the study area, is the second most urbanized indigenous settlement in Nigeria after Kano. Unlike Kano however, Ibadan is located in the rain forest vegetation belt where rainfall abounds for a minimum of 8 months in a year and mean annual temperature is around $27^{\circ} \mathrm{C}$, providing perfect environmental conditions for all-year-round mosquito breeding. With its urbanized status also come mixed land-uses with residential land-use accounting for more than $61 \%$ of the land-use types in the city (Ayeni, 1994). This land-use type includes high, medium and low density residential areas as well as government acquisitions for housing and military barracks. The residential density categories, at a glance, project a social stratification suggesting a direct relationship between levels of social wellbeing and places of residence. Both the environmental conditions and the population stratification along residential density lines make Ibadan unique for a study as this.

\section{Literature Review and Theoretical Framework Socio-Economic Status and Malaria}

Outside of changes in climatic parameters of temperature, rainfall and humidity as well as changes in land use and land cover which have been shown to promote the breeding of mosquito and increase the prevalence of malaria (Adeboyejo et al, 2012; Zacarias and Andersson, 20ll, Krefis et al, 20l I; Oluleye and Akinbobola, 2010; Uneke and Ibeh, 2008; Johnson et al, 2008; Munga et al, 2006; Vittor et al, 2006; Patz et al, 2005;), Yusuf, et al, (2010) investigated the effects of poverty on childhood malaria at regional levels using Nigeria as a case study. Their findings indicated that the prevalence of the disease was highest among children from the poorest households while it was minimal among children from wealthier households. The finding is not significantly different from those of regional studies in India (Sharma, 2003) and in several countries of the world (Teklehaimanot and Mejia, 2008; Worrall et al, 2003; Gwatkin and Guillot, 2000; Gwatkin et al, 2000) where it has been established that malaria is a disease of poverty. This is more so as only $0.2 \%$ of global malaria deaths are found in the world's richest population quintile while $57.9 \%$ of global malaria deaths are concentrated among the world's poorest population quintile (Gwatkin and Guillot, 2000).

Further, CHESTRAD (2000) observed that individuals earning less than $\$ 1.00$ a day suffered more bouts of malaria per month than their counterparts with more income. The study was based on a sample from 4 states in Nigeria. Using occupation as a corollary of socio-economic status; greater risk occupations like agriculture and farming are associated with low socio-economic status (Worral et al, 2003), Ghebreyesus et al (2000) found out that highland migrant agricultural labourers in Ethiopia are more at risk of malaria than their counterparts in other forms of employment. Gemstone miners (Yapabandara and Curtis, 2002) and rice farmers (Mutero et al, 2000) were also 
found to have a greater risk of being infected with malaria. Tshikuka et al (1996) also showed that the prevalence of malaria parasite was higher among workers in the low socio-economic occupational category (low paid, industrial or unskilled workers) than among workers in a socio-economic category.

Location as a socio-economic factor influencing malaria prevalence is often described with respect to the rural-urban dichotomy while household facilities and age / condition of buildings are mostly implied by housing as a socio-economic factor affecting the prevalence of malaria. Rasheed et al (2000) for instance found out that annual episodes of fever were higher among children who lived in rural areas of Benin Republic in contrast to their counterparts in the urban areas. The same findings were recorded in studies in Malawi (Ndawala et al, 2000), Zaire (Coene, 1993) and South-Western Nigeria (Ademowo et al, 1995). Some other studies focused their locational analysis essentially on the spatial variation of the prevalence pattern within the urban milieu. Prathiba and Marshall (2012) for instance discovered that most breeding sites of mosquitoes in the urban areas are artificial (ditches, agricultural sites etc.) and are mostly found in the peri-urban where the socio-economic status of residents is usually lower than what obtains in the city centers.

The result is not significantly different from findings in studies by Byrne (2007), Wang et al (2005) and Robert et al (2003). In their own locational analysis within the context of urban environment, Kumar et al (20/4) identified malaria hotspots in Chennai, India and associated these hotspots to local climatic factors in the affected areas. They however suggested that the socioeconomic status of the inhabitants of the hotspot areas may have an effect on their findings. As a generalization, Worrall et al (2003) argue that housing that places individuals at increased risk of malaria infection is used more frequently by those in the lower socio-economic strata than those in higher socioeconomic strata. These houses are agglomerated along residential district lines with distinct class boundaries. In other words, income and occupation, among other factors, influence choices of housing and housing standards, are spatially concentrated, and are all a reflection of socio-economic status.

\section{Disease Triangle and Health Inequality}

The concept of disease triangle, also known as the human ecology of disease, is concerned with the ways human behavior, in its cultural and socioeconomic context, interacts with environmental conditions to produce or prevent disease among susceptible people (Meade, Florin and Gesler, 1988). It sees disease production and prevention as consequent on the people's reaction to the physical environment. The concept provides explanation for the variation in space of human disease and health using three dimensions of habitat (environment), population and cultural behavior. While habitat in the triangle comprises both the biotic and abiotic elements of the environment, population is concerned with humans as organisms and hosts of diseases. The observable aspect of culture emanating from cultural precepts, economic constraints, social norms and individual psychology is implied by behaviour in the disease triangle.

The concept of disease triangle is apt in the analysis of the spatial variations of malaria essentially because malaria is largely habitat dependent and its prevalence is affected by habitat, population and behaviour. For example, while the mosquito vector breeds well in puddles of still water found around the home or in unhygienic water storage conditions within the home, its continued existence is encouraged or discouraged by conditions within the home. Such conditions include whether windows are screened, cleanliness of the toilets, bathrooms and kitchen, adequacy of ventilation and the availability of temperature regulation facilities among others. These conditions are mostly affected by income and socioeconomic status; both of which are attributes of population in the disease triangle.

The locations of health facilities and by extension, access to healthcare are also a part of habitat and they also affect the prevalence of diseases as health personnel provide education on prevention and control of disease as well as provide treatments, and these are usually spatially uneven (Adewoyin, 2015; Okafor, 2007; Ikporuko, 1987 for instance) and skewed positively towards the elites. Lipton (1998; 1977) posits that as long as elites' interests, background and sympathies remain largely urban, resource allocation will always favour the elites. The elites live in the best part of a city (Harvey, 1975; Smith, 1979; 1994), characterized by low residential density and good environmental quality. Studies have also shown that health-care in particular is more accessible to people of higher socio-economic groups who live in the best parts of a city (Townsend, 1974; Knox, 1978) than to the relatively poor who live in high or medium density residential areas. This situation is known as the inverse care law (Hart, 197I) and the underclass hypothesis (Lineberry, 1976).

An individual's lifestyle is simply his behaviour. How the individual adapts to conditions in his habitat, 
the choices he makes to contain changes in his habitat and on his person is that individual's behaviour. In the disease triangle, behaviour includes the actions and inactions of an individual that expose him to or protect him from diseases as well as other interventions aimed at achieving a sound health. Behavior thus includes disease prevention and treatment strategies employed by an individual and these are also consequent on the individual's education, income, cultural perceptions and socioeconomic status.

\section{Data and Methods}

\section{Population and Sampling}

Ibadan had a population of 2,550,593 according to the 2006 provisional census figures and covers an area of $3,080 \mathrm{~km}^{2}$. The city's population is spread across II Local Government Areas (LGAs) namely; Akinyele, Ido, Egbeda, Ona-Ara, Lagelu and Oluyole. Others are Ibadan North, North-West, North-East, South-West and Ibadan South-East local government areas. The latter set of 5 LGAs constitutes metropolitan Ibadan while the former set is suburban Ibadan. The focus of the study was on the 5 metropolitan LGAs. The metropolitan LGAs are more urbanized and possess more diversification in terms of social stratification, occupation, and residential characteristics. The 5 metropolitan LGAs comprised 168 localities (NPC, 1991; 2006) and accounted for about $53 \%$ of the population of the study area.

Using a stratified sampling technique, localities of contrasting housing residential densities, typifying high density, medium density and low density residential neighbourhoods in each LGA were selected for the study. With the background of an average of 4 persons per household in Ibadan (NBS, 2009), the selected localities were computed to have 43,377 households of which I,084 (2.5\%) were randomly selected in each locality for sampling. The selected localities, their residential density category, number of households and sample size from each of the localities are shown in Table I.

\section{Data Sources, Collection and Analyses}

In measuring social well-being, a generic term for levels of living, quality of life, social satisfaction, and standard of living (Coates, Johnston and Knox, 1977; Smith, 1979), indicators such as access to healthcare, food and nutrition, education, shelter and clothing, conditions of work and nature of employment, as well as income and aggregate savings were employed. Other measures include quality of the living environment, recreation and leisure, security and social inclusion (UN, 1954; Smith, 1973; Drewnowski, 1974; Coates et al, 1977). An aggregation of these indicators (broken down into 26 variables) was measured in this study as primary data to determine the population's levels of social wellbeing. Data on the number of times each household treated episodes of malaria (for both the household heads and members of the households) was also sourced as primary data from the households to measure susceptibility to malaria and general wellness. The data on social well-being and frequency of being sick with malaria were collected using structured questionnaire administered on I,084 household heads in the selected localities.

The responses were coded to reflect numerical magnitude where 5 represented the best/highest rating and I represented the worst/least rating for social well-being measurement while for frequency of malaria treatment, 5 represented treatment frequency of 10 and more times annually and 1 represented treatment frequency of less than 5 times in a year. A simple addition of each respondent's feedback on all the 26 indicators measuring social well-being was thereafter carried out to determine each respondent's level of social well-being. Based on the computation, an individual with a perfect quality of life would have scored the highest 5 marks for each of the 26 variables and would have a maximum obtainable score of $130(5 \times 26)$. The scores were standardized to $100 \%$ for inter-locality comparison and establishment of quartile ranges.

The relationships between the indices of social well-being were analyzed using Chi Square Test while intra-urban variations in social well-being were analyzed using the One-Way Analysis of Variance (ANOVA). The Spearman Rank Correlation technique was used to establish the relationship between levels of social well-being and residential densities. The composite score derived for each respondent reflecting his/her level of social well-being was correlated with the respondent's frequency of household malaria treatment using the Pearson Product Moment Correlation technique. 
Table I: Distribution and Characteristics of Selected Localities

\begin{tabular}{|c|c|c|c|c|c|c|c|}
\hline $\mathrm{S} / \mathrm{N}$ & $\begin{array}{l}\text { Local } \\
\text { Government } \\
\text { Area }\end{array}$ & $\begin{array}{l}\text { No of } \\
\text { Localities }\end{array}$ & $\begin{array}{l}\text { Selected } \\
\text { Localities }\end{array}$ & $\begin{array}{l}\text { Residential } \\
\text { Density }\end{array}$ & $\begin{array}{l}\text { Population } \\
\text { of Selected } \\
\text { Localities }\end{array}$ & $\begin{array}{l}\text { Computed } \\
\text { Number of } \\
\text { Households }\end{array}$ & $\begin{array}{l}\text { Number of } \\
\text { Questionnaire } \\
\text { Administered }\end{array}$ \\
\hline \multirow[t]{3}{*}{1} & Ibadan North & 41 & Ikolaba & Low & 6,575 & I,644 & $4 \mid$ \\
\hline & & & Basorun & Medium & 4,156 & 1,039 & 26 \\
\hline & & & Yemetu & High & 11,763 & 2,941 & 74 \\
\hline \multirow[t]{3}{*}{2} & Ibadan NW & 30 & Idi-Isin & Low & 2,398 & 600 & 15 \\
\hline & & & Eleyele & Medium & 18,949 & 4,737 & 118 \\
\hline & & & Abebi & High & $|1,87|$ & 2,968 & 74 \\
\hline \multirow[t]{3}{*}{3} & Ibadan NE & 35 & Agodi & Low & 8,959 & 2,240 & 56 \\
\hline & & & $\begin{array}{l}\text { Old Ife } \\
\text { Road }\end{array}$ & Medium & 11,903 & 2,976 & 74 \\
\hline & & & Elekuro & High & 12,300 & 3,075 & 77 \\
\hline \multirow[t]{3}{*}{4} & Ibadan SE & 32 & Felele & Low & 22,136 & 5,534 & 138 \\
\hline & & & Challenge & Medium & 10,675 & 2,669 & 67 \\
\hline & & & Idi-Aro & High & 10,047 & 2,512 & 63 \\
\hline \multirow[t]{4}{*}{5} & Ibadan SW & 30 & $\begin{array}{l}\text { Oluyole } \\
\text { Estate }\end{array}$ & Low & 5,097 & 1.274 & 32 \\
\hline & & & Molete & Medium & 5,293 & 1,323 & 33 \\
\hline & & & Foko & High & 31,384 & 7,846 & 196 \\
\hline & & & Total & & & 43,377 & 1,084 \\
\hline
\end{tabular}

Source: NPC (1991), Authors' Computation (2015)

\section{Results and Discussion}

\section{Spatial Pattern of Social Well-Being}

From the analysis of the social well-being scores of the I,084 respondents, the mean of the entire data set is 57.71 while the quartile boundaries are $50.00 \%, 57.69 \%$ and $63.85 \%$. The $1^{\text {st }}$ quartile is the lowest social well-being class while the $4^{\text {th }}$ quartile is the highest social well-being class. The minimum standard score for a respondent in the entire data set was $35.38 \%$ while the maximum was $87.69 \%$. The scores were recorded in Foko and Idi-lsin respectively.

Over $63 \%$ of the respondents in Foko lived within the $I^{\text {st }}$ quartile of the standard of living scale whereas all the respondents from Idi-Isin were within the $4^{\text {th }}$ quartile. Apart from Foko, other localities with the bulk of their population on the lowest rung of the standard of living scale were Idi-Aro and Elekuro. Over $90 \%$ of the population in Abebi lived within the first 2 quartiles. While Yemetu had a spread across each of the quartiles, the bulk of its population was found within the $2^{\text {nd }}$ quartile whereas Idi-Isin, Oluyole and Agodi had no respondents within the $I^{\text {st }}$ quartile just as Abebi and Elekuro had no respondents within the $4^{\text {th }}$ quartile.

The lowest mean score for a locality was $48.29 \%$ for Foko while $78.97 \%$ for Idi-Isin was the highest mean score for a locality. Apart from Foko, the lowest locality mean scores were for the high density residential localities of Idi-Aro (49.6I\%), Elekuro $(50.23 \%)$ and Abebi (50.4l\%). The Z-Scores of each locality's mean scores on the social well-being indices were used to map the ranks of the localities as illustrated in Figure I. The population in Idi-Isin ranked best, followed by the population in Oluyole, Ikolaba, Basorun, Felele and Agodi. Foko, Idi-Aro, Elekuro, Abebi and Yemetu brought up the rear. 


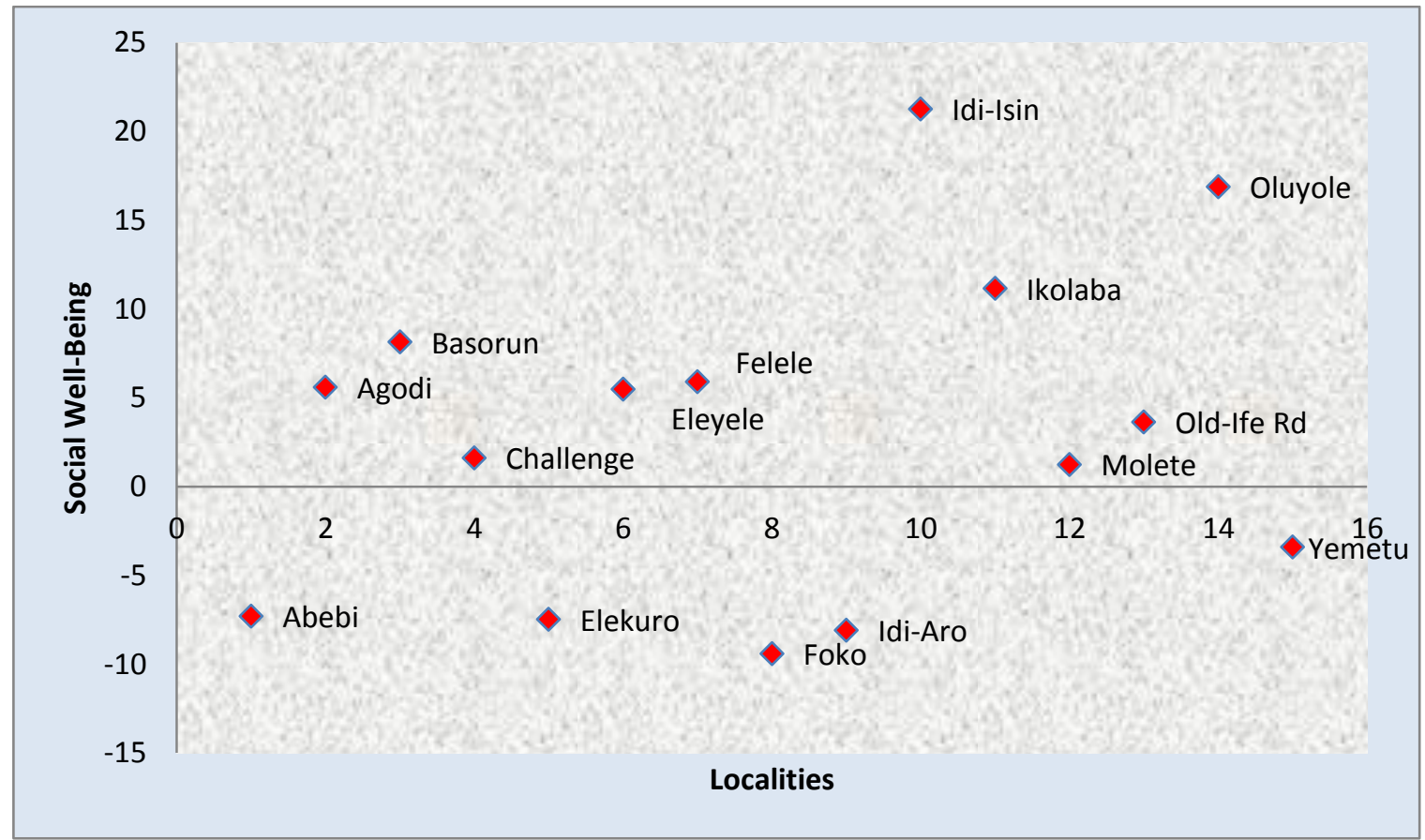

Figure I: Spatial Pattern of Social Well-Being

Source: Authors' Analysis, 2015

\section{Social Well-Being and Residential Density Categories}

The distribution of the respondents on the social well-being scale was further analyzed along residential density lines. The analyses followed three vistas; a comparison of social well-being scores of respondents resident in each of the residential density category, an investigation of the variations in levels of social well-being among the residential categories, and an assessment of the relationships between the two variables in the residential categories. Measures of Central Tendency were used for the first analysis while the One-Way Analysis of Variance (ANOVA) statistical technique was employed for the second analysis. The Spearman Rank Correlation technique was employed for the assessment of relationship.

A minimum social well-being score of 35.38 was recorded among the respondents from the high density residential area while the highest score was 66.92. In the medium density localities, the highest score was 79.23 while it was 87.69 in the low density residential areas. The average scores of respondents in each of the residential categories were 50.01, 61.73 and 66.38 for high, medium and low density residential areas respectively. This gives a variance (from the aggregate mean of 57.7I) of $-7.70,4.02$ and 8.67 for the high, medium and low density residential areas respectively. The result shows that levels of social well-being were best in the low density localities and lowest in the high density localities. On the aggregate, residents of high density localities lived below the average level of social well-

being in the study area as typified by a negative value of the residential category mean deviation from the total sample mean. On the average too, residents of both the medium and low density residential localities lived better than the sample average quality of life in the study area.

This variation in quality of lives among the three residential categories was also tested and found to be statistically valid. The result of the One-Way ANOVA indicates that with an F-Value of $5 \mathrm{I} 2.463$ and a confidence level of $99.9 \%(P=0.001)$, there is a spatial variation in levels of social well-being among the residential categories and that the variations are statistically significant. This implies that people of different levels of social well-being populate different residential categories. The nature of the variations was further tested to determine the direction and level of relationship between the levels of social wellbeing and places of residence.

The residential categories were ranked I for high density, 2 for medium density and 3 for low density. The result of the correlation analysis shows that there is a strong positive relationship $(r=0.710, P=$ 0.001 ). The result implies that levels of social wellbeing are positively correlated with residential densities and that the best levels of social well-being are found in the low density residential areas. In 
other words, quality of lives is best in low density residential areas.

\section{Spatial Pattern of Household Incidence of Malaria} In Eleyele, $59.32 \%$ of the respondents treated malaria between 5 and 9 times in a year while in Felele, Molete, Old-Ife Road and Yemetu, the proportion of respondents who treated malaria between 5 and 9 times annually were $59.42 \%$, $63.64 \%, 58.11 \%$ and $66.22 \%$ respectively. In Elekuro, 38 of the 77 respondents treated malaria at least 10 times in a year while in Foko, more than $57 \%$ of the respondents treated malaria at least 10 times annually. The proportion of respondents in IdiAro who treated malaria at least 10 times annually was $55.56 \%$ whereas only $9.38 \%$ and $13.33 \%$ of the population in Oluyole Estate and Idi-Isin respectively were in this category.

When the results are analyzed along residential density lines, respondents from the 5 high density residential localities accounted for $62.9 \%$ of those who treated malaria in their households 10 times and more annually while $20.9 \%$ and $16.2 \%$ of the respondents in this category were from the medium density and low density residential areas respectively. About $52 \%$ of the respondents who treated household malaria less than 5 times per annum were from the low density residential areas. The result of the Analysis of Variance in the incidence of malaria ( $F$ $=65.778, P=0.00 \mathrm{I}$ ) indicates that at the household level in different residential density category, there is a significant spatial variation in the incidence of malaria. In other words, incidence of malaria in the study area varies from one household to another based on the residential density category the household belongs. A summary of the responses indicates that $60 \mathrm{I}$ respondents $(55.4 \%)$ treated malaria in their households between 5 and 9 times annually. A total of 383 respondents representing $35.3 \%$ of the total respondents also treated malaria at least 10 times in a year in their individual households while only $9.2 \%$ of the total respondents treated malaria less than 5 times in a year.

\section{Social Well-Being and Incidence of Malaria}

The analyses of the correlation between levels of social well-being and incidence of malaria were carried out on two fronts; based on the household responses along locality lines and based on aggregated responses of the 1,084 respondents. The results at the household levels within each locality indicate that with the exception of Ikolaba and Idi-
Isin, all the localities recorded significant negative correlations. The highest correlation coefficients were recorded in Elekuro, Foko, Idi-Aro and Abebi. The coefficients $(r)$ were $-0.700,-0.674,-0.664$ and 0.657 for the afore-mentioned localities respectively. The correlation coefficients for the four localities were also statistically significant at $P=0.01$ (2tailed). Basorun, Oluyole Estate, Eleyele and Molete also recorded correlation coefficients greater than 0.5 and in all the cases too, the correlations were significant at $\mathrm{P}=0.0 \mathrm{I}$ level. In Agodi, the correlation coefficient was -0.320 and significant at $P=0.05$ level. At the aggregated level, the result shows a correlation coefficient $r=-0.578$ and a $99 \%$ confidence level (2-tailed).

These results confirm that at the household levels across the localities, there is a negative correlation between levels of social well-being and frequency of being sick with malaria. The results also imply that an individual household's frequency of being sick with malaria is inversely proportional to that household's levels of social well-being. The relationship between social well-being and incidence of malaria as shown by the results is also strong as indicated by the various correlation coefficients. The negative correlation coefficients in the results indicate that as the socio-economic status of the individual, measured by his social well-being scores increases, the individual becomes less prone to malaria. Stretched further, it means incidence of malaria is higher among individuals with low socio-economic status.

\section{Conclusion}

From the foregoing, it has been established that levels of social well-being vary significantly along residential density lines with residents of low density residential localities having a higher level of quality of lives than their counterparts in both the medium and high density residential neighbourhoods. The least levels of social well-being in the study area were observed in the high density residential areas. Also, the study showed that about $63 \%$ of the respondents who treated episodes of malaria at least 10 times in a year were resident in the high density residential districts, implying that incidence of household malaria was highest in the high density residential areas. The study also established that there is a strong inverse correlation between levels of social well-being and incidence of malaria in the study area.

It follows from these findings therefore, that there is an agglomeration of people of same (or almost same) socioeconomic status within the same clearly defined residential districts and that based on the residential differentiation, levels of social well-being 
vary directly with the quality of the residential categories. This results in a spatial variation in health outcomes such that the most affected, by virtue of their low socioeconomic status, are resident in high density residential neighbourhoods while the least affected are the more affluent and are resident in low density neighbourhoods. In other words, residents of low density residential areas ranked highest in social well-being and had the best health outcomes evidenced by the lowest incidence of malaria among the three residential classes.

The study has therefore established that there is a direct relationship between levels of social wellbeing and the quality of the residential habitat on the one hand, and that health outcomes are consequent on the interaction between social wellbeing and places of residence. It follows therefore that to achieve significant improvement in diseases prevention and eradication, primacy should be accorded the role of socioeconomic and environmental determinants of health. Instituting socioeconomic programmes to improve the quality of life of the population and a deliberate locational bias in favour of other parts of an urban center not inhabited by the affluent, in the provision of public goods, services, and urban development programs, are clear steps a government interested in a just and disease-free society can pursue to ensure every citizen enjoys a good life irrespective of where $\mathrm{s} /$ he resides.

\section{REFERENCES}

Adeboyejo, A.T., Lirvhuwani, M and Shonisani, D.K. (2012) Impact of Climate Change on Children's Health in Limpopo Province, South-Africa. International Journal of Environmental Research and Public Health, 9.

Ademowo, O.G., Falusi, A.G. and Mewoyeka, O.O. (1995) Prevalence of Asymptomatic Parasitaemia in an Urban and Rural Community in South Western Nigeria. Central African Journal of Medicine, 4 I (I)

Adewoyin, $Y$ (20I5) Urbanization and Health Inequalities in Ibadan, Nigeria. A paper at the International Conference on Cities and Informal Urbanization, Ogbomoso, Nigeria

Anderson, N.B and Armstead, C.A. (1995) Toward Understanding the Association of Socioeconomic Status and Health: A New Challenge for the Biopsychosocial Approach. Psychosomatic Medicine, 13.

Ayeni, B. (1994) The Metropolitan Area of Ibadan: Its Growth and Structure. In Filani, M.O., Akintola, F.O. and Ikporukpo, C.O. (eds) Ibadan Region. Ibadan: Rex Charles
Barker, D. and Osmond, C. (1987) Inequalities in Health in Britain: Specific Explanations in Three Lancashire Towns. British Medical Journal, 294.

Ben-Shlomo, Y., White, I.R. and Marmot, M. (1996) Does the Variation in the Socioeconomic Characteristics of an Area Affect Mortality? British Medical Journal $3 / 2$.

Byrne, N. (2007) Urban Malaria Risk in Sub-Saharan Africa: Where is the Evidence? Travel Medicine and Infectious Disease, 5 (2).

CHESTRAD (2000). Malaria, Povery and Health, Center for Health Services Training. Research and Development International.

Coates, B.E., Johnston, R.J. and Knox, P.L. (1977) Geography and Inequality. London: OUP

Coene, J. (1993) Malaria in Urban and Rural Kinshasa: the Entomological Input. Medical \& Veterinary Entomology, 7 (2)

Drewnowski, J. (1974) On measuring and Planning the Quality of Life. The Hague: Mouton

Egunjobi, L. (1995) Urban Environmental Health and Physical Planning. In lyun, B.F., Verhasselt, Y. and Anthony, H. (eds) The Health of Nations: Medicine, Disease and Development in the Third World. Avebury; Aldershot

Ghebreyesus T. A., Witten K. H., Getachew A., Yohannes, A.M., Tesfay, W., Minass, M., Bosman, A. and Teklehaimanot, A. (2000) The Community Based Malaria Control Programme in Tigray, Northern Ethiopia. A Review of Programme SetUp, Activities, Outcomes and Impact. Parassitologia 42.

Gwatkin, D.R., Rutstein, S., Johnson, K., Pande, R.P. and Wagstaff, A. (2000) Socio-Economic Differences on Health, Nutrition and Population. World Bank.

Gwatkin, D.R and Guillot, M. (2000) The Burden of Disease among the Global Poor. World Bank

Hart, J.T. (197I) The Inverse Care Law. Lancet I.

Harvey, D. (1975) Class Structure in a Capitalist Society and the Theory of Residential Differentiation. In Peet, Chisolm and Haggett (eds.). Processes in Physical and Human Geography. London, Heineman.

Ikporukpo, C.O. (1987) An analysis of the Accessibility of Public Facilities in Nigeria. SocioEconomic Planning Science, 2I (I).

lyun, B.F. (1987) Ecology and Disease in Nigeria. Geographica Medica 17

Johnson, M.F., Gomez, A. and Pinedo-Vasquez, M. (2008) Land Use and Mosquito Diversity in the Peruvian Amazon. Journal of Medical Entomology, 45 
Kaplan, G. (1996) People and Places; Contrasting Perspectives on the Association between Social Class and Health. International Journal of Health Services 26.

Kaplan, G., Pamuk, E., Lynch, J.W., Cohen, R.D. and Balfour, J.L. (1996) Inequality in Income and Mortality in the United States: Analysis of Mortality and Pathways. British Medical Journal, $3 / 2$

Kawachi, I and Kennedy, B.P. (1997) Socio-Economic Determinant of Health: Health and Social Cohesion, Why Care about Income Inequality? British Medical Journal 314

Kennedy, B.P., Kawachi, I. and Prothrow-Stith, D. (1996) Income Distribution and Mortality: CrossSectional Ecological Study of the Robin Hood Index in the United States. British Medical Journal $3 / 2$

Knox, P.L. (1978) The Intra Urban Ecology of Primary Medical Care; Patterns of Accessibility and their Policy Implications. Environment \& Planning AI 0

Krefis, A.C., Schwarz, N.G., Nkrumah, B., Acquah, S., Loag, W., Oldeland, J., Sarpong, N., AduSarkodie, Y., Ranft, U. and May, J. (20II) Spatial Analysis of Land Cover Determinants of Malaria Incidence in the Ashanti Region, Ghana. Plos One.

Kumar, D.S., Andimuthu, R., Rajan, R. and Venkatesan, M.S. (20/4) Spatial Trend, Environmental and Socioeconomic Factors Associated with Malaria Prevalence in Chennai. Malaria Journal (13)

Lineberry, R. (1976) Equality, Public Policy and Public Services: The Underclass Hypothesis and the Limits to Equality. Policy and Politics 4.

Lipton, M. (1977) Why the Poor Stay Poor. London: Temple Smith.

Lipton, M., 1998 Urban bias and inequality. In Seligson, M. and Passe-Smith, J.T.(eds.): Development and Underdevelopment: The Political Economy Of Global Inequality. London: Lynne- Reinne

Macintyre, S., Ellaway, A. and Cummins, S. (2002) Place Effects on Health; How can We Conceptualize, Operationalize and Measure Them? Social Science and Medicine 55.

Malaria Foundation International, (20/3) HYPERLINK " http:// www.malaria.org"

Meade, M., Florin, J., Gesler, W. (1988) Medical Geography. New York: The Guilford Press

Munga, S., Minakawa, N, Zhou, G., Mushinzimana, E., Barak, O.O. (2006) Association between Landcover and Habitat Productivity of Malaria
Vectors in Western Kenyan Highlands. American Journal of Tropical Medicine and Hygiene, 74

Mutero C. M., Blank H., Konradsen F. and van der Hoek W. (2000) Water Management for Controlling the Breeding of Anopheles Mosquitoes in Rice Irrigation Schemes in Kenya. Acta Tropica 76

National Bureau of Statistics, (2009) Social Statistics in Nigeria. Abuja; FG Press

National Malaria Elimination Programme, (2014) National Malaria Strategic Plan 2014 - 2020. Federal Ministry of Health, Abuja.

National Population Commission, (1991) 199| Provisional Census Figures

National Population Commission, (2006) 2006 Provisional Census Figures

Ndawala J., Kalanda G. and Mahy M. (2000). Malawi MDHS Data Analysis, Malawi National Statistics Office.http://www.nso.malawi.net/

Nigeria, (2013) President's Malaria Initiative; Malaria Operations Plan. FG Press.

Okafor, S.I. (2007) Location, Distribution, and Questions of Justice. An Inaugural Lecture, University of lbadan. Ibadan, IUP.

Oluleye, A. and Akinbobola A. (2010) Malaria and Pneumonia Occurrence in Lagos, Nigeria: Role of Temperature and Rainfall. African Journal of Environmental Science and Technology. Vol 47.

Patz, J.A., Campbell-Lendrum, D., Holloway T. and Foley J.A. (2005) Impact of Regional Climate Change on Human Health. Nature, Vol 438.

Prathiba, M. and Marshall, J. (20/2) Factors Contributing to Urban Malaria Transmission in Sub-Saharan Africa: A Systematic Review. Journal of Tropical Medicine, 2012

Rashed S., Johnson H., Dongier P., Moreau, R., Lee, C., Lambert, J. and Schaffer, C. (2000) Economic Impact of Febrile Morbidity and Use of Permethrin-Impregnated Bednets in a Malarious area II. Determinants of Febrile Episodes and the Cost of their Treatment and Malaria Prevention. American Journal of Tropical Medicine and Hygiene 62

Reiter, P. (2000) From Shakespeare to Defoe; Malaria in England in the Little Ice Age. Emerging Infectious Diseases 6 (I).

Robert, V., Macintyre, K., Keating, J., Trape, J.F., Duchemin, J.B., Warren, M. and Beier, J.C. (2003) Malaria Transmission in Urban Sub-Saharan Africa. American Journal of Tropical Medicine and Hygiene, 68 (2)

Sharma, V.P. (2003) Malaria and Poverty in India. Current Science, 84. 
Smith, D.M. (1973) The Geography of Social Well Being in the U.S. New York: McGraw Hill

Smith, D.M. (1979) Where the Grass is Greener. Living in an Unequal World. Harmondsworth: Penguin Books.

Tshikuka J. G., Scott M. E., Gray-Donald K. and Kalumba O. N. (1996) Multiple Infection with Plasmodium and Helminths in Communities of Low and Relatively High Socio-Economic Status. Annals of Tropical Medical Parasitology 90.

Uneke, C and lbeh, L. (2008) Impacts of Deforestation on Malaria in South-Eastern Nigeria; the Epidemiological, Socio-Economic and Ecological Implications. Internet Journal of Third World Medicine, 8.

United Nations, (1954) Economic Survey of Europe. Quoted in Smith, D.M., 1979 ibid.

United Nations Task Team on the Post-2015 UN Development Agenda (2012) Health in the Post2015 UN Development Agenda. Thematic Think Piece

Vittor, A.Y., Gilman, R.H., Tielsch, J., Glass, G., Shields, T., Lozano, W.S., Pinedo-Cancino, $V$ and Patz, J.A. (2006) The Effect of Deforestation on the Human-Biting Rate of Anopheles Darlingi; The Primary Vector of Falciparum Malaria in the Peruvian Amazon. American Journal of Tropical Medicine and Hygiene, 74

Wang, S.J., Lengeler, C., Smith, T.A., Vounatsou, P., Diadie, D.A., Pritroipa, X., Convelbo, N., Kientga, M. and Tanner, M. (2005) Rapid Urban Malaria Appraisal (RUMA) I: Epidemiology of Urban Malaria in Ouagadougou," Malaria Journal, 4

Wilkinson, R.G. (1992) Income Distribution and Life Expectancy. British Medical Journal, 304

Wilkinson, R.G. (1996) Unhealthy Societies: The Afflictions of Inequality. London: Routeledge

Worrall, E., Basu, S. and Hanson, K. (2003) The Relationship between Socioeconomic Status and Malaria: A review of the Literature, SES and Malaria, January 2003

World Health Organization, (2005) World Malaria Report.

World Health organization, (2006) World Malaria Report

Yapabandara, A. M. and Curtis C. F. (2002) Laboratory and Field Comparisons of Pyriproxyfen Polystyrene Beads and other Larvicidal Methods against Malaria Vectors in Sri Lanka. Acta Tropica 8I.

Yusuf, O.B., Adeoye, B.W., Oladepo, O.O., Peters, D.H. and Bishai, D. (2010) Poverty and Fever
Smith, D.M. (1994) Geography and Social Justice. Oxford, Blackwell

Teklehaimanot, A. and Meija, P. (2008) Malaria and Poverty. New York Academy of Science

Townsend, P. (1974) Inequality and Health Services. Lancet I

Vulnerability in Nigeria; A Multi-Level Analysis. Malaria Journal, 9.

Zacarias, O.P. and Andersson, M. (201 I) Spatial and Temporal Patterns of Malaria Incidence in Mozambique. Malaria Journal, 10 (189). 